\title{
TINJAUAN SANITASI SEKOLAH DASAR NEGERI I PLIKEN DI WILAYAH DESA PLIKEN KECAMATAN KEMBARAN KABUPATEN BANYUMAS TAHUN 2018
}

\author{
Gustin Isniarti $^{1)}$, Budi Triyantoro ${ }^{2)}$ \\ Jurusan Kesehatan Lingkungan, Polteknik Kesehatan Kemenkes Semarang, \\ Jl. Raya Baturaden KM 12 Purwokerto, Indonesia
}

\begin{abstract}
Abstrak
Derajat kesehatan merupakan interaksi dari empat faktor, yakni lingkungan, pelayanan kesehatan, perilaku dan keturunan. Upaya Kesehatan Sekolah (UKS) merupakan salah satu upaya peningkatan derajat kesehatan masyarakat di sekolah. Sara sanitasi sekolah merupakan usaha preventif, yang didalamnya meliputi: penyediaan jamban, penyediaan air bersih, tempat pombuangan sampah, sarana pembuangan air limbah dan ruang kelas dan bangunan yang sehat. Tujuan penelitian ini adalah untuk mengetahui kondisi sanitasi Sekolah Dasar Negeri 1 Pliken Kecamatan Kembaran Kabupaten Banyumas Tahun 2018. Metode Penelitian ini yaitu Deskriptif dengan tujuan memperoleh gambaran tentang kondisi sanitasi. Subjek penelitian SD Negeri 1 Pliken. Data yang digunakan adalah data primer dan sekunder. Hasil penelitian menunjukkan bahwa kondisi sanitasi sekolah dasar negeri 1 Pliken kecamatan kembaran kabupaten banyumas tahun 2018 belum seтиа memenuhi persyaratan kesehatan. Peningkatan kesehatan di sekolah untuk peningkatan upaya sanitasi yang ada, sehingga mengurangi faktor resiko yang berdampak lingkungan.
\end{abstract}

Kata Kunci : Sanitasi; Sekolah Dasar; Kesehatan Lingkungan

\begin{abstract}
Health degree is an interaction of four factors, there is environment, health service, behaviour and offspring. School Health Effrots/Upaya Kesehatan Sekolah (UKS) are mean the step up of the people healt degree at school. Another facilities and infrastructur are the precaution and consist of toilet povision, clean water povision, trash can provision, the waste disposal facilities healty class environment and building This purpose research is getting depiction of the sanitation condition of SD Negeri 1 Pliken in the year 2018. The research method is descriptive with goal to get the view about sanitaion condition. Research subject $S D$ Negeri 1 Pliken. The data that used are primary and secondary data. Research result shows the sanitation condition of SD Negeri 1 Pliken year 2018 has not met the health requaire ments standards. The healt improvement at shcool from existing sanitation improvement have to be done so that environtmen influece of the risk factor can be reduced.
\end{abstract}

Keywords: Sanitation; Basic School; Enviromental Health 


\section{Pendahuluan}

Pembangunan kesehatan bertujuan untuk meningkatkan kesadaran, kemauan, dan kemampuan hidup sehat bagi setiap orang agar terwujud derajat kesehatan masyarakat yang setinggi-tingginya, sebagai investasi bagi pembangunan sumber daya manusia yang produktif secara sosial dan ekonomis. Pembangunan kesehatan merupakan bagian dari pembangunan nasional yang bertujuan untuk mewujudkan derajat kesehatan yang optimal bagi semua lapisan masyarakat yang merupakan faktor dominan bagi tercapainya pembangunan nasional (UU RI. No 36 Tahun 2009).

Usaha peningkatan kesehatan lingkungan di sekolah merupakan salah satu program Usaha Kesehatan Sekolah (UKS) yang bertujuan untuk meningkatkan derajat kesehatan masyarakat di sekolah. Peningkatan kesehatan lingkungan sekolah sangat penting karena sekolah merupakan tempat berkumpulnya anak didik, guru, dan orang lain dimungkinkan terjadinya penularan penyakit. Untuk mencegah terjadinya penularan penyakit dalam lingkungan sekolah serta untuk mendukung program kesehatan lingkungan yang sehat maka perlu adanya sarana sanitasi sekolah yang memenuhi syarat (UU No. 26 Tahun 2003).

Usaha Sanitasi adalah merupakan usaha preventif, yang usahanya dititik beratkan kepada penghindaran penyakit atau gangguan kesehatan lain yang disebabkan oleh faktor faktor lingkungan hidup. Didalam sanitasi lingkungan sekolah terdapat beberapa persyaratan yang harus dipenuhi antara lain: Penyediaan Jamban, Penyediaan Air Bersih, Tempat Pembuangan Sampah, Sarana Pembuangan Air Limbah, dan Ruang kelas dan bangunan yang sehat.

Desa Pliken termasuk dalam wilayah Puskesmas II Kembaran Kecamatan Kembaran Kabupaten Banyumas, dengan jumlah penduduk 8.712 jiwa. Sarana pendidikan yang ada di Desa Pliken adalah sebagai berikut: Sekolah Dasar sebanyak 4 sekolah, Madrasah Ibtidaiyah sebanyak 1 sekolah.

Sarana sanitasi Sekolah Dasar di Desa Pliken Kecamatan Kembaran terutama sanitasi yang meliputi ruang kelas dan bangunan sekolah, jamban sekolah, penyediaan air bersih, tempat pembuangan sampah, sarana pembuangan limbah, penyediaan makanan dan minuman dan pengendalian vektor sebagian masih ada yang belum memenuhi syarat. Kondisi sekolah yang kurang baik sanitasinya ini dapat berpengaruh terhadap proses belajar mengajar, hal ini dapat menimbulkan gangguan kesehatan, misalnya: menurunkan konsentrasi belajar, meningkatkan risiko penularan penyakit berbasis lingkungan seperti ISPA, penyakit kulit, diare, demam berdarah, malaria dan lain-lain.

Sekolah Dasar Negeri 1 Pliken merupakan salah satu sekolah dasar yang ada di Desa Pliken, dimana SD tersebut mempunyai jumlah siswa yang 200 murid. Berdasarkan hasil survey pendahuluan yang telah dilakukan oleh peneliti di sekolah dasar ini masih terdapat aspek sanitasi yang belum memenuhi syarat, diantaranya selain kurangnya sarana penyediaan jamban sekolah, sarana yang ada juga dalam keadaan tidak bersih, ventilasi di setiap ruangan juga masih tidak memenuhi syarat.

Memperhatikan latar belakang tersebut di atas, maka peneliti tertarik untuk mengangkat permasalahan ini pada Karya Tulis Ilmiah yang berjudul "Tinjauan Sanitasi Sekolah Dasar Negeri 1 Pliken di Wilayah Desa Pliken Kecamatan Kembaran Kabupaten Banyumas Tahun 2018".

\section{Bahan dan Metode}

Penelitian ini termasuk jenis penelitian Deskriptif dengan dengan tujuan memperoleh gambaran tentang kondisi sanitasi.

Waktu dalam penelitian ini dibagi menjadi 3 tahap yang pertama tahap persiapan November - Febuari 2018, tahap pelaksanaan Maret - Juli 2018, tahap penyelesaian Juli 2018

Cara pengumpulan data dengan data primer diambil dari objek/objek penelitian oleh peneliti perorangan maupun organisasi. Data primer pada penelitian ini berasal dari responden, dengan cara peneliti mengukur suhu, kelembaban, pencahayaan ruangan, observasi dan wawancara.

Desain penelitian yang digunakan dalam penelitian ini adalah penelitian deskriptif, dengan tujuan untuk memperoleh gambaran tentang kondisi sanitasi Sekolah Dasar Negeri 1 Pliken di Wilayah Desa Pliken Kecamatan Kembaran Tahun 2018

Analisis yang digunakan dalam penelitian adalah deskriptif dengan menguraikan hasil hasil survey yang disajikan dalam bentuk tabel.

III. Hasil dan Pembahasan

\section{A. Gambaran Umum}

Keadaan Geografi

Sekolah Dasar Negeri 1 Pliken adalah sekolah negeri yang bernaung dibawah Kementrian Pendidikan dan Kebudayaan dan beralamat di Pliken RT 05 RW 02, 
Kelu-rahan Pliken Kecamatan Kembaran Kabupaten Banyumas Provinsi Jawa Tengah. SD Negeri 1 Pliken ini memiliki luas tanah sebesar $14.522 \mathrm{~m} 2$, dimana tempatnya mudah diakses oleh masyarakat termasuk sumber air dan sumber listrik.

Kenaikan jumlah siswa Sekolah Dasar Negeri 1 Pliken Kecamatan Kembaran terjadi meningkat dalam 2 tahun terakhir ini. Hal ini dapat dilihat dari perbandingan jumlah siswa SD lain yang ada di wilayah Desa Pliken Kecamatan Kembaran, yaitu sebanyak 203 siswa.

Jumlah ruang kelas yang ada di SD Negeri 1 Pliken sebanyak 11 ruang, dimana terdiri dari 7 ruang kelas, 1 ruang guru, 1 ruang kepala sekolah, 1 ruang tata usaha, dan 1 ruang dapur.

\section{B. Gambaran Khusus}

1. Persyaratan Kesehatan Bangunan Sekolah Dasar Negeri 1 Pliken

Kondisi lingkungan dan bangunan sekolah

\begin{tabular}{|c|c|c|c|c|c|c|c|c|}
\hline \multirow{3}{*}{$\begin{array}{l}\mathrm{N} \\
\mathrm{O} \\
.\end{array}$} & \multirow{3}{*}{ Sekolah } & \multicolumn{7}{|c|}{ Nilai } \\
\hline & & \multicolumn{2}{|c|}{ Lokasi } & \multicolumn{2}{|c|}{$\begin{array}{l}\text { Lingkung- } \\
\text { an }\end{array}$} & \multicolumn{2}{|c|}{$\begin{array}{l}\text { Bangun- } \\
\text { an }\end{array}$} & \multirow{2}{*}{$\begin{array}{c}\begin{array}{c}\text { Rata- } \\
\text { rata }\end{array} \\
\%\end{array}$} \\
\hline & & Nilai & $\%$ & Nilai & $\%$ & Nilai & $\%$ & \\
\hline $\begin{array}{l}1 \\
.\end{array}$ & $\begin{array}{l}\text { SD } \\
\text { Negeri } 1 \\
\text { Pliken }\end{array}$ & 16 & 80 & 13 & 65 & 16 & $\begin{array}{l}8 \\
0\end{array}$ & 75 \\
\hline
\end{tabular}

Berdasarkan tabel 4.1 letak

SD Negeri 1 Pliken berlokasi tidak terlalu jauh dengan industri, tidak terletak di daerah rawan bencana dan bekas tempat pembuangan akhir sampah. Lokasi ini sesuai dengan KepmenKes RI

No.1429/MENKES/SK/XII/2006

tentang persyaratan kesehatan lingkungan seko-lah lokasi bangunan sekolah tidak terletak pada daerah rawan bencana, bekas tempat pembuangan akhir (TPA). Lingkungan SD Negeri 1 Pliken bersih, sudah dilengkapi pagar keliling, me-mungkinan menjadi tempat berkembang biakan vektor. Untuk itu, pem-bersihan halaman sekolah harus dilakukan minimal sehari satu kali. Hal ini belum sesuai dengan persyaratan kesehatan lingkungan menurut Direktorat Jendral PPM dan PL tahun 2000, yaitu bersih, tidak memungkinkan sebagai tempat bersarang serangga dan tikus, dapat mencegah masuk dan berkem-bang biak binatang pengganggu lain dan dilengkapi dengan pagar. Bangunan SD Negeri 1 Pliken secara keseluruhan kokoh dan tidak menjadi tempat bersarang vektor. Keadaan seperti ini sudah sesuai dengan persya-ratan kesehatan lingkungan menurut Dirjen PPM dan PL Depkes RI tahun 2006, yaitu bangunan kokoh, dan tidak memungkinkan menjadi tempat berkembang biak vektor.

2. Persyaratan Kesehatan Ruang Kelas

Konstruksi Ruang Kelas

\begin{tabular}{ccccccccc}
\hline & & \multicolumn{7}{c}{ Nilai } \\
\cline { 3 - 8 } No & Sekolah & \multicolumn{2}{c}{ Lokasi } & \multicolumn{2}{c}{$\begin{array}{c}\text { Lingkung- } \\
\text { an }\end{array}$} & $\begin{array}{c}\text { Bangun- } \\
\text { an }\end{array}$ & $\begin{array}{c}\text { Rata- } \\
\text { rata }\end{array}$ \\
\cline { 3 - 8 } & Nilai & $\%$ & $\begin{array}{c}\text { Nil } \\
\text { ai }\end{array}$ & $\%$ & $\begin{array}{c}\text { Nil } \\
\text { ai }\end{array}$ & $\%$ & $\%$ \\
\hline & $\begin{array}{l}\text { SD } \\
\text { Negeri }\end{array}$ & 10 & 100 & 10 & 100 & 10 & 100 & 75 \\
\hline
\end{tabular}

(a terbuat dari bahan keramik, bahan kuat, permukaan rata dan tidak licin. Keadaan lantai seperti ini sesuai dengan KepMenKes RI No.1429/MENKES/SK/XII/2006 tentang persyaratan kesehatan lingkungan sekolah, yaitu lantai harus terbuat dari bahan yang kuat, kedap air, permukaan rata, tidak retak, tidak licin dan mudah dibersihkan, lantai harus berwarna terang. Keadaan dinding yaitu permukaan dinding harus bersih, tidak lembab dan berwarna terang. Permukaan dinding yang selalu terkena percikan air harus dibuat kedap air. Keadaan atap yaitu atap harus kuat, tidak bocor, dan tidak menjadi tempat perindukan tikus. Kemiringan atap harus cukup agar tidak memungkinkan terjadinya genangan air. Kondisi langit-langit di SD 1 Pliken mempunyai tinggi 3,5 meter dari lantai, terbuat dari bahan kuat dan bersih. Untuk itu pembersihan langit - langit dilakukan minimal seminggu sekali. Hal ini belum sesuai dengan KepMenKes RI No.1429/MENKES/SK/XII/2006

tentang Persyaratan Kesehatan Lingkungan Sekolah, yaitu langit langit harus kuat, berwarna terang, mudah dibersihkan, tinggi langit langit minimal 3,25 m dari lantai. Pencahayaan di SD Negeri 1 Pliken terang dan tidak menyilaukan. Hal ini sesuai dengan KepMenKes RI 
No.1429/MENKES/SK/XII/2006

tentang persyaratan kesehatan lingkungan sekolah yaitu pencahayaan di ruang kelas tidak menyilaukan. Luas ventilasi di SD Negeri 1 Pliken dari 20\% dari luas lantai, tinggi kisi-kisi jendela pintu sudah lebih dari $2,5 \mathrm{c}$ dari lantai dan ventilasi menghadap ke udara bebas. Untuk itu sebaiknya setiap pagi jendela dibuka agar terjadi penghawaan/aliran udara segar yang memadai di dalam ruangan untuk men-jamin kesehatan penghuninya. hal ini belum sesuai dengan KepMenKes RI No.1429/MENKES/SK/XII/2006

tentang persyaratan kesehatan lingkungan sekolah yaitu luas ventilasi minimal $20 \%$ dari luas lantai.

3. Fasilitas Sanitasi Sekolah a. Penyediaan Air Bersih

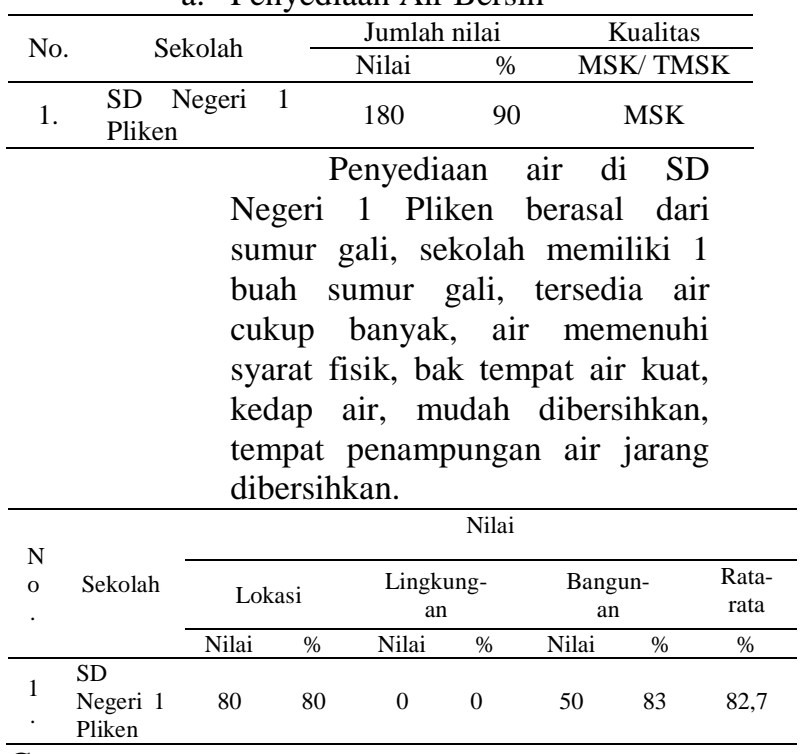

Catatan :

Total nilai maksimum untuk aspek kesehatan kamar mandi $=100$

Total nilai maksimum untuk aspek kesehatan peturasan $=90$

Total nilai maksimum untuk aspek kesehatan pembuangan air limbah $=60$

Berdasarkan tabel 4.5 dapat diketahui bahwa penyediaan kamar mandi dan jamban di SD Negeri 1 Pliken dalam kondisi kurang bersih dan berbau, tersedia cukup air, terdapat 3 kamar mandi yang ventilasi menghadap udara bebas dan 2 kamar mandi kurang mendaptkan udara bebas, terpisah laki-laki dan perempuan, tidak tersedia tempat sampah tertutup, tersedia alat pember-sihan, perbandingan jumlah jamban dengan siswa belum sesuai, jumlah kamar kamar mandi dan jamban sebanyak 5 buah kamar mandi. Hal ini belum sesuai dengan KepMenKes RI/No. 1429/MENKES/SK/XII/2006 tentang Per-syaratan Kesehatan Lingkungan Sekolah, yaitu proporsi jumlah $1 \mathrm{WC}$ untuk 25 orang. Peturasan dalam kondisi bersih, terdapat pembersih, tersedia tempat sampah di setiap kamar mandi. Saluran pembuangan air limbah, system aliran tertutup, limbah cair yang berasal dari jamban dan yang berupa tinja disalurkan ke septictank.

b. Sarana Pembuangan Sampah

\begin{tabular}{ccccccc}
\cline { 3 - 6 } No. & Sekolah & \multicolumn{2}{c}{$\begin{array}{c}\text { Tempat } \\
\text { Sampah }\end{array}$} & \multicolumn{2}{c}{ TPS } & Rata-rata \\
\cline { 3 - 6 } & Nilai & $\%$ & Nilai & $\%$ & $\%$ \\
\hline 1. & $\begin{array}{l}\text { SD } \\
\text { Negeri 1 } \\
\text { Pliken }\end{array}$ & 45 & 75 & 30 & 50 & 62,5 \\
\hline
\end{tabular}

Catatan :

Total nilai maksimum untuk aspek kesehatan tempat sampah $=60$

Total nilai maksimum untuk aspek kesehatan TPS $=60$

Berdasarkan tabel 4.6 dapat diketahui bahwa penyediaan tempat sampah di SD Negeri 1 Pliken, yaitu terdapat tempat sampah terbuat dari bahan yang kuat, ringan, kedap air, tutup mudah dibuka dan tidak mengotori tangan, jumlah dan volume sesuai dengan produksi sampah, sampah pada masingmasing ruang setiap hari selalu dibuang, tetapi belum ada pemisahan antara tempat sampah antara sampah kering dan basah. Sebaiknya pengelola sekolah menyediakan tempat sampah berpenutup dan yang sudah ada pemisahan sampah menurut jenisnya.

Berdasarkan pengamatan yang dilakukan di SD Negeri 1 Pliken kondisi TPS belum permanen, menjadi sarang vektor, mudah dijangkau kendaraan sampah, dilakukan pengangkutan sampah. Oleh karena itu sebaiknya menye-diakan TPS 
yang memenuhi syarat kesehatan. Hal ini belum sesuai dengan KepMenKes

RI No.1429/MENKES/SK/XII/2006 tentang persyaratan kesehatan lingkungan sekolah yaitu tersedia TPS dari seluruh ruang untuk memudahkan pengangkutan atau pemusnahan sampah.

\begin{tabular}{|c|c|c|}
\hline & c. & $\begin{array}{l}\text { Pengelolaan } \\
\text { Minuman }\end{array}$ \\
\hline \multirow{3}{*}{$\begin{array}{l}\mathrm{N} \\
\mathrm{o}\end{array}$} & \multirow{3}{*}{ Sekolah } & Nilai \\
\hline & & $\begin{array}{cc} & \text { Kualitas } \\
\text { Rata-rata } & \text { MSK/ } \\
& \text { TMSK }\end{array}$ \\
\hline & & Nilai \\
\hline \multirow[t]{2}{*}{1.} & $\begin{array}{l}\text { SD } \\
\text { Negeri } \\
\text { Pliken }\end{array}$ & MSK \\
\hline & & $\begin{array}{l}\text { Berdasarkan tabel } 4.7 \\
\text { dapat diketahui bahwa ruang } \\
\text { dapur di SD Negeri } 1 \text { Pliken } \\
\text { kurang bersih, lantai kuat, kedap } \\
\text { air, tidak licin, mudah } \\
\text { dibersihkan, sirkulasi udara } \\
\text { lancar, tersedia tempat sampah, } \\
\text { tetapi tidak tertutup, terdapat } \\
\text { tempat cuci tangan, terdapat lap } \\
\text { dan sabun, tidak terdapat kantin } \\
\text { sekolah. Kondisi tempat sampah } \\
\text { di ruang dapur belum memenuhi } \\
\text { persyaratan karena masih terbuka, } \\
\text { sehingga memungkinkan } \\
\text { dijangkau oleh serangga, tikus } \\
\text { dan lalat. Untuk menghindari hal } \\
\text { tersebut sebaiknya pengelola } \\
\text { menyediakan tempat sampah yang } \\
\text { berpenutup. Pembersihan dapur } \\
\text { dilakukan lebih sering, minimal } \\
\text { 2x sehari. }\end{array}$ \\
\hline
\end{tabular}

4. Pengendalian Vektor

\begin{tabular}{|c|c|c|c|}
\hline \multirow{2}{*}{ No. } & \multirow{2}{*}{ Sekolah } & \multicolumn{2}{|c|}{ Nilai Pengendalian Vektor } \\
\hline & & Nilai & $\%$ \\
\hline 1. & $\begin{array}{ll}\text { SD Negeri } & 1 \\
\text { Pliken } & \end{array}$ & 15 & 75 \\
\hline
\end{tabular}

Berdasarkan tabel 4.8 dapat

diketahui bahwa pengendalian vektor di SD Negeri 1 Pliken, cara mencegah tikus masuk adalah menggunakan perangkap tikus. Hal ini perlu ditingkatkan untuk mencegah berbagai macam penularan penyakit yang disebarkan oleh serangga dan tikus.
5. Luas Ventilasi

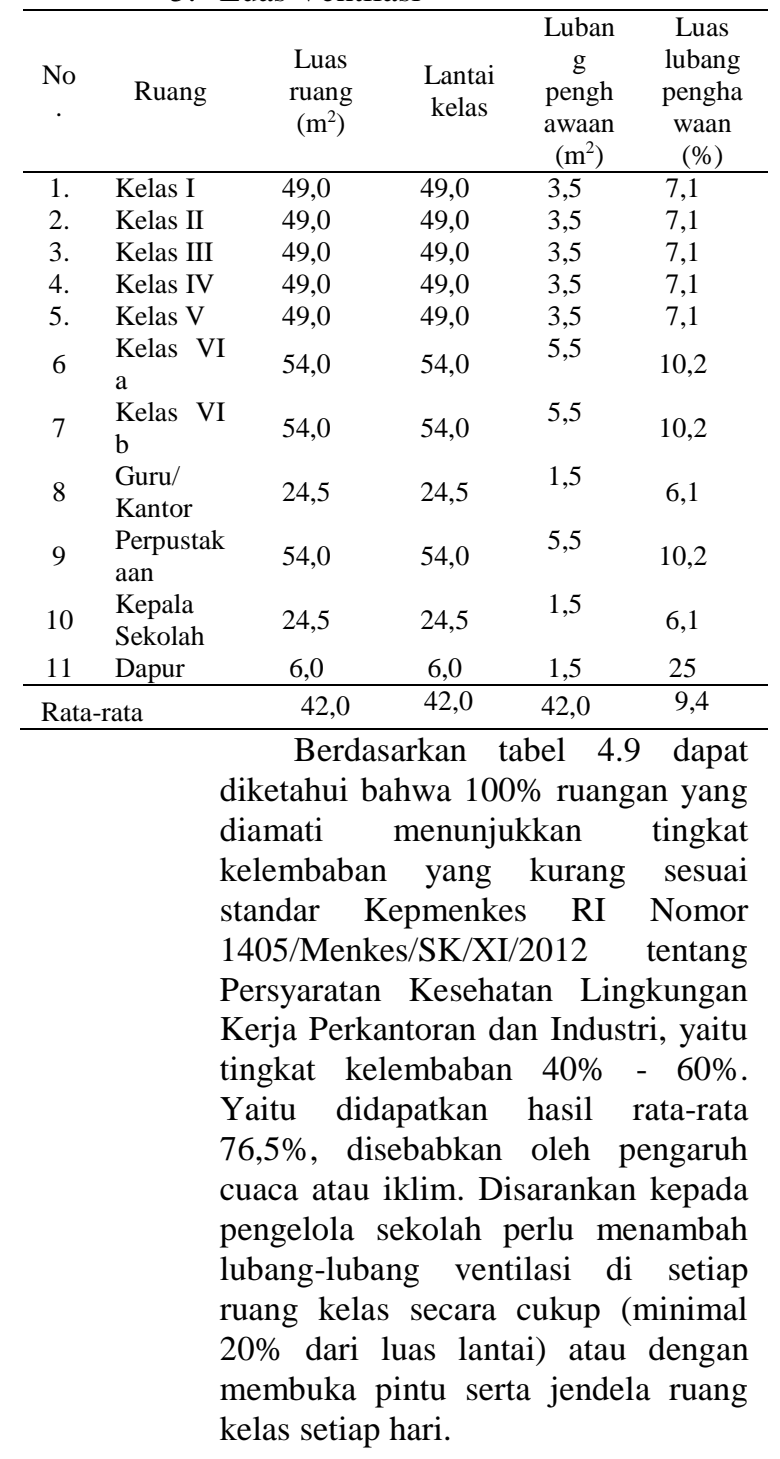

6. Hasil Pengukuran

a. Pencahayaan

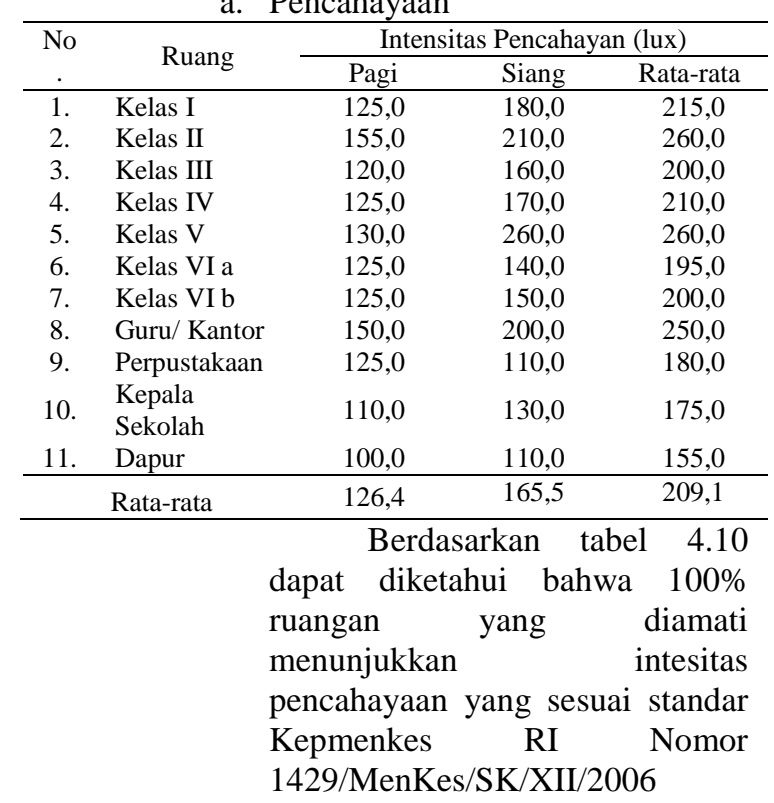


tentang

Pedoman

Penyelenggaraan Kesehatan

Llingkungan Sekolah, yaitu intensitas pencahayaan ruang kelas 100-300 lux. Ini sangat baik untuk ruang belajar murid-murid memudahkan mereka dalam membaca dan berkomunikasi satu dengan yang lain, tetapi perlu dicegah tidak terjadi kesilauan, misalnya dengan pemasangan gordyn pada jendela-jendela ruang kelas.

b. Suhu

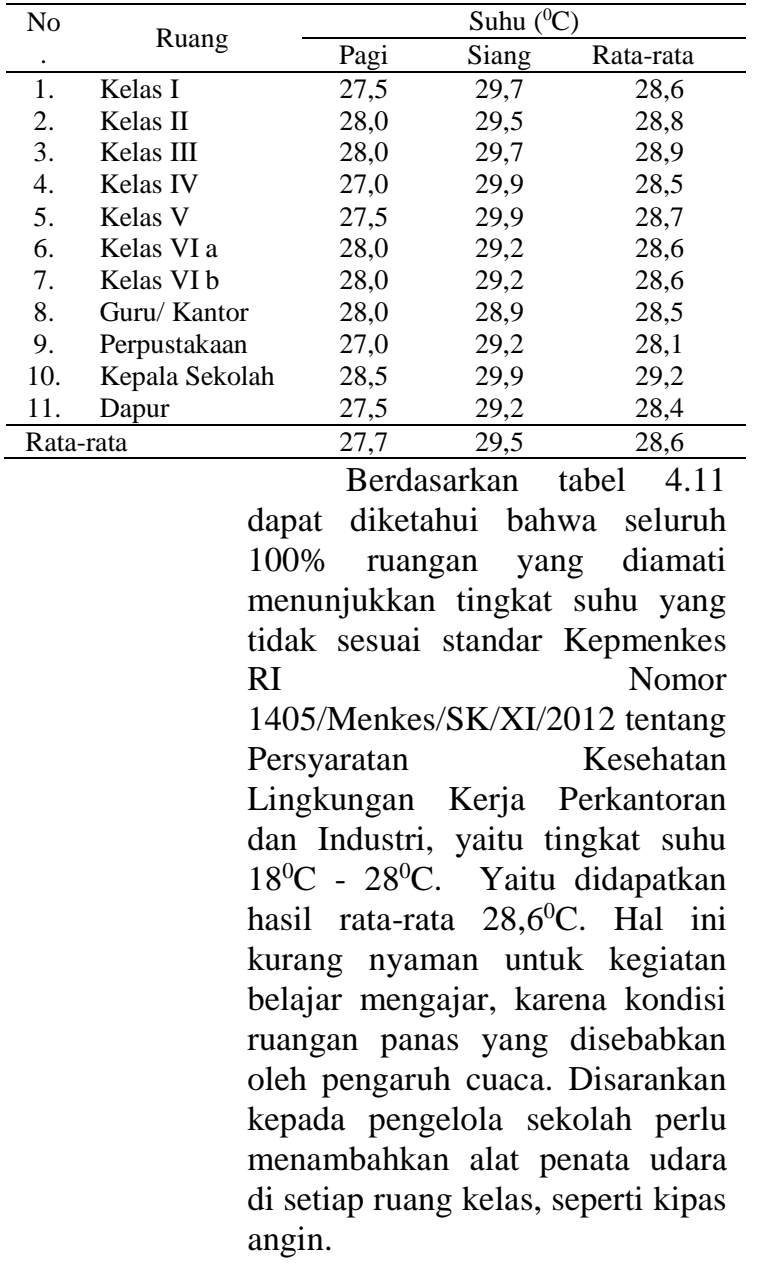

\begin{tabular}{|c|c|c|}
\hline No. & Ruang & $\begin{array}{c}\text { Kelembaban } \\
(\%)\end{array}$ \\
\hline 1. & Kelas I & 75,5 \\
\hline 2. & Kelas II & 75,6 \\
\hline 3. & Kelas III & 75,5 \\
\hline 4. & Kelas IV & 78,8 \\
\hline 5. & Kelas V & 78,6 \\
\hline 6. & Kelas VI a & 75,9 \\
\hline 7. & Kelas VI b & 75,9 \\
\hline 8. & Guru/ Kantor & 75,8 \\
\hline 9. & Perpustakaan & 75,9 \\
\hline 10. & $\begin{array}{l}\text { Kepala } \\
\text { Sekolah }\end{array}$ & 78,5 \\
\hline 11. & Dapur & 75,0 \\
\hline \multicolumn{2}{|c|}{ Rata-rata } & 76,5 \\
\hline
\end{tabular}

C. Hasil Penilaian Kondisi Sanitasi Sekolah Dasar Secara Umum

\begin{tabular}{|c|c|c|c|}
\hline \multirow[b]{2}{*}{ No. } & \multirow[b]{2}{*}{ Komponen Pemeriksaan } & \multicolumn{2}{|c|}{ SD Negeri 1 Pliken } \\
\hline & & $(\%)$ & $\begin{array}{l}\text { Keterang } \\
\text { an }\end{array}$ \\
\hline \multirow{8}{*}{$\begin{array}{l}1 . \\
2 . \\
3 .\end{array}$} & 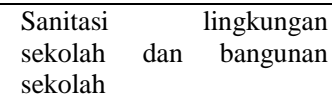 & 75,0 & MSK \\
\hline & Sanitasi ruang kelas & & \\
\hline & Sanitasi sekolah & & \\
\hline & a. Penyediaan air bersih & 90,0 & MSK \\
\hline & $\begin{array}{l}\text { b. Penyediaan kamar } \\
\text { mandi dan jamban }\end{array}$ & 80,0 & MSK \\
\hline & $\begin{array}{l}\text { c. Sarana pembuangan } \\
\text { air limbah }\end{array}$ & 83,0 & MSK \\
\hline & d. $\begin{array}{l}\text { Sarana pembuangan } \\
\text { sampah }\end{array}$ & 62,5 & TMSK \\
\hline & $\begin{array}{l}\text { e. Pengelolaan makanan } \\
\text { dan minuman }\end{array}$ & 90,0 & MSK \\
\hline 4. & Pengendalian vector & 75,0 & MSK \\
\hline \multicolumn{2}{|c|}{ Rata-rata } & 79,3 & \\
\hline & \multicolumn{3}{|c|}{$\begin{array}{l}\text { diketahui bahwa ada } 1 \text { ruangan yang tidak } \\
\text { memenuhi syarat kesehatan lingkungan } \\
\text { sekolah secara umum, yakni yang mendapat } \\
\text { prosentase kurang dari } 75 \% \text {. Disarankan } \\
\text { pada ruangan yang belum memenuhi syarat } \\
\text { ini upaya peningkatan kesehatan lingkungan } \\
\text { sekolah secara maksimal, untuk menjaga } \\
\text { kesehatan para murid, guru, karyawan dan } \\
\text { masyarakat sekitarnya. }\end{array}$} \\
\hline
\end{tabular}

IV. Kesimpulan dan Saran

A. Kesimpulan

1. Kondisi sanitasi Sekolah Dasar Negeri 1 Pliken wilayah Desa Pliken Kecamatan Kembaran Kabupaten Banyumas Tahun 2018, didapatkan hasil bahwa kondisi lingkungan dan bangunan sekolah sudah memenuhi syarat kesehatan, yaitu dengan rata-rata sebesar $75 \%$.

2. Kondisi ruang kelas Sekolah Dasar Negeri 1 Pliken wilayah Desa Pliken Kecamatan Kembaran Kabupaten Banyumas Tahun 2018, didapatkan hasil bahwa pembagian ruang kelas sudah memenuhi syarat kesehatan hanya masalah kebersihan perlu ditingkatkan.

3. Fasilitas sanitasi Sekolah Dasar Negeri 1 Pliken wilayah Desa Pliken Kecamatan Kembaran Kabupaten Banyumas Tahun 2018, yang diamati tentang penyediaan air bersih sudah memenuhi syarat kesehatan.

4. Fasilitas sanitasi Sekolah Dasar Negeri 1 Pliken wilayah Desa Pliken Kecamatan Kembaran Kabupaten Banyumas Tahun 2018, yang diamati tentang penyediaan kamar mandi/ WC dan peturasan sudah memenuhi 
persyaratan kesehatan, akan tetapi perlu ditingkatkan lagi kebersihannya. Perbandingan jumlah siswa dengan jumlah jamban masih kurang sesuai.

5. Fasilitas sanitasi Sekolah Dasar Negeri 1 Pliken wilayah Desa Pliken Kecamatan Kembaran Kabupaten Banyumas Tahun 2018, yang diamati tentang pembuangan air limbah sudah memenuhi syarat kesehatan.

6. Fasilitas sanitasi Sekolah Dasar Negeri 1 Pliken wilayah Desa Pliken Kecamatan Kembaran Kabupaten Banyumas Tahun 2018, yang diamati tentang pembuangan sampah dan TPS belum memenuhi syarat kesehatan.

7. Fasilitas sanitasi Sekolah Dasar Negeri 1 Pliken wilayah Desa Pliken Kecamatan Kembaran Kabupaten Banyumas Tahun 2018, yang diamati tentang pengelolaan makanan dan minuman sudah memeuhi syarat kesehatan.

8. Pengendalian vektor Sekolah Dasar Negeri 1 Pliken wilayah Desa Pliken Kecamatan Kembaran Kabupaten Banyumas Tahun 2018, cara pengenaliannya menggunakan perangkap tikus yang ditempatkan di tempat-tempat tertentu.

9. Ventilasi ruang kelas Sekolah Dasar Negeri 1 Pliken wilayah Desa Pliken Kecamatan Kembaran Kabupaten Banyumas Tahun 2018, 20\% dari luas lantai.

10. Pencahayaan ruang kelas Sekolah Dasar Negeri 1 Pliken wilayah Desa Pliken Kecamatan Kembaran Kabupaten Banyumas Tahun 2018, yang diamati sudah memenuhi syarat kesehatan yaitu rata-rata 209,1 lux.

11. Suhu ruang kelas Sekolah Dasar Negeri 1 Pliken wilayah Desa Pliken Kecamatan Kembaran Kabupaten Banyumas Tahun 2018, yang diamati belum memenuhi syarat kesehatan yaitu $28,6^{\circ} \mathrm{C}$.

12. Kelembaban ruang kelas Sekolah Dasar Negeri 1 Pliken wilayah Desa Pliken Kecamatan Kembaran Kabupaten Banyumas Tahun 2018, yang diamati masih kurang sesuai standar kesehatan yaitu $9,4 \%$

B. Saran

Disarankan kepada sekolah bagi ruangan yang belum memuhi syarat/ standar kesehatan perlu dilakukan upaya peningkatan kesehatan lingkungan di sekolah, untuk menjaga kesehatan para murid, pegawai dan masyarakat sekitarnya, khususnya sanitasi sekolah.

\section{Daftar Pustaka}

Aziz Alimul Hidayat, 2007, Metode Penelitian Kebidanan dan Analisa Data. Jakarta: Salemba Medika.

Budiman Chandra, 2006, Pengantar Kesehatan Lingkungan, Jakarta: EGC.

Chasan S Kusnadi. 2006, Pengendalian Vektor dan Binatang Pengganggu, Makassar: Institut Penerbitan Jurusan Kesehatan Lingkungan Poltekkes Makassar.

Departemen kesehatan R.I. 1990. Permenkes no. 416/menkes/per/ix/1990. tentang SyaratSyarat dan Pengawasan Kualitas Air Minum, Jakarta.

Departemen Kesehatan R.I. Direktorat Jendral Pengendalian Penyakit Menular dan Penyehatan Lingkungan, 2007, Pedoman Teknis Pengendalian Faktor Resiko Kesehatan Lingkungan di Sekolah, Jakarta: DIT.JEN.PPM dan PL.

Departemen Kesehatan R.I. 1999, Petunjuk Teknis Penyuluhan Program Penyehatan Lingkungan Permukiman bagi Petugas Puskesmas, Jakarta: Direktorat Jendrall Pemberantasan Penyakit Menular dan Penyehatan Lingkungan Pemukiman.

Departemen Kesehatan R.I. 1992, Pelatihan Kader Kesehatan Lingkungan. Jakarta: Dirjen PPM Dan PLP.

Direktorat jendral PP dan PL. 2010, Kursus Hygiene Sanitasi Makanan dan Minuman: Jakarta.

http://kangmoes.com/artikel-definisi-sekolah.html, diakses tanggal 15 Januari 2013 pukul $11.00 \mathrm{WIB}$.

\section{http://kenikwno}

files.wordpress.com/2010/08panduan sarana sanitasi di sekolah.pdf, di akses tanggal 13 Januari 2013 pukul 11.00 WIB.

Indan, Entjang. 2000, Ilmu Kesehatan Masyarakat, Bandung: Penerbit Alumni.

Keputusan Menteri Kesehatan. 2002, Kepmenkes No.1405/Menkes/SK/XI/2002, tentang Persyaratan Kesehatan Lingkungan Kerja, Jakarta: Kementrian Kesehatan RI. 